\title{
The Role of the Intestine in Iron Kinetics
}

\author{
Marcel E. Conrad, Lewis R. Weintraub, and William H. Crosby with the \\ technical assistance of Betty Merrill and Arthur Foy \\ (From the Departments of Hematology and Gastroenterology, Walter Reed Army Institute \\ of Research, Washington, D. C.)
}

The iron content of the body is small, amounting to about 60 parts per million (1). This quantity must remain within narrow limits to prevent the development of either siderosis or iron deficiency. It has been postulated that the metabolic balance of the body's iron is maintained solely by controlled absorption and that excretion plays a minor role (2). Hahn and his associates proposed that the iron content of the intestinal mucosa controlled the quantity of iron absorbed by the body (3). More recent views are that the iron content of the gut is unimportant in the regulation of iron metabolism (4).

This paper reports a study of the iron content of the intestine and its role in the regulation of iron equilibrium.

\section{Methods}

Male albino rats, Walter Reed Carworth Farms strain, weighing 225 to $275 \mathrm{~g}$ were used. The principles of laboratory animal care as promulgated by the National Society for Medical Research were observed. The rats were raised in a pathogen-free environment and housed in galvanized wire cages or plastic metabolic cages. Their diet contained $15 \mathrm{mg}$ of iron per $100 \mathrm{~g}$ of dry weight; the average ingestion of iron was estimated to be $2 \mathrm{mg}$ daily. During prolonged excretory studies irondeficient rats were fed an iron-deficient powdered-milk diet.

Iron deficiency was induced 5 days before study by bleeding rats $5 \mathrm{ml}$, which removed $2.5 \mathrm{mg}$ of hemoglobin iron. Blood was let by insertion of a heparinized capillary tube into the medial retro-orbital venous plexus. Rats were iron loaded by im injection of 12.5 to $25 \mathrm{mg}$ of iron as Imferon 2 weeks before study. Intravenous doses of iron $^{\text {s0 }}$ were injected through the dorsal vein of the penis. A dose of $5 \mu \mathrm{c}$ of ferrous ${ }^{50}$ citrate $(1 \mu \mathrm{g}$ of iron) was used, a quantity that could be bound by the

* Submitted for publication September 23, 1963; accepted January 14, 1964.

Presented in part at the Fifty-fifth Annual Meeting of the American Society for Clinical Investigation, Atlantic City, N. J., April 1963, and published in abstract form (J. clin. Invest. 1963, 42, 926). unsaturated transferrin available in $1 \mathrm{ml}$ of normal plasma.

The segments of gut used in this study were excised from freshly killed animals, washed in tap water, and opened lengthwise. The intestinal lumen was washed free of contents in running tap water and then rinsed in iron-free distilled water. Intestinal segments used for chemical analysis were obtained from rats after a 16-hour fast. Gut segments were prepared for chemical analysis in a Virtis tissue homogenizer. Nonheme iron content was measured by a modification of the method of Brückmann and Zondek (5). After development of the color reaction, turbidity was cleared from the chemical reaction mixtures by ultracentrifugation for 30 minutes at $25,000 \mathrm{rpm}$. Radioautographs of tissue specimens were obtained by a method described previously (6).

Iron absorption studies of an oral test dose of radioiron $^{59}$ were performed by measurement of total body radioactivity in a small animal whole-body liquid scintillation detector (Packard ARMAC). Whole-body radioactivity of $(0.8 \mathrm{Mev} \longrightarrow \infty)$ was measured 3 hours and 7 days after the oral dose of radioiron $^{50}$ to determine the percentage of the tracer absorbed by rats. The test dose was $0.5 \mu \mathrm{c}$ of ferrous $^{59}$ citrate in a carrier of $0.25 \mathrm{mg}$ ferrous sulfate dissolved in $0.5 \mathrm{ml}$ of distilled water; it was administered through an olive-tipped 17-gauge endoesophageal tube to rats fasted for 16 hours. Standards were prepared for each experiment by measuring an identical test dose of iron $^{50}$ into a $250-\mathrm{ml}$ water-filled plastic bottle. The animals, restrained in vented $\frac{3}{4}$-quart ice cream cartons, were counted for 200 seconds, as was the appropriate reference standard. Net counts were calculated by subtracting background radioactivity. The ratios of net animal counts 3 hours after the test dose $\left(r_{0}\right)$ to those of the reference standard $\left(s_{o}\right)$ were used as the $100 \%$ value. Similar ratios $\left(r_{x} / s_{x}\right)$ at later intervals were compared to the reference value to determine the proportion of retained radionuclide.

$$
\frac{r_{x} / s_{x}}{r_{o} / s_{o}} \times 100=\begin{aligned}
& \text { percentage of retention of } \\
& \text { radionuclide at time } x .
\end{aligned}
$$

To determine the radioactivity in cumulative stool collections and in specimens of the small intestine, the materials were first digested in acid and diluted with distilled water to $250 \mathrm{ml}$ in plastic bottles. Then radioactivity was quantified as in the test animals. The reliability of this technique has been reported previously (7).

Radioactivity in small specimens (colon, stomach, samples of stool) was measured in a well-type crystal scin- 

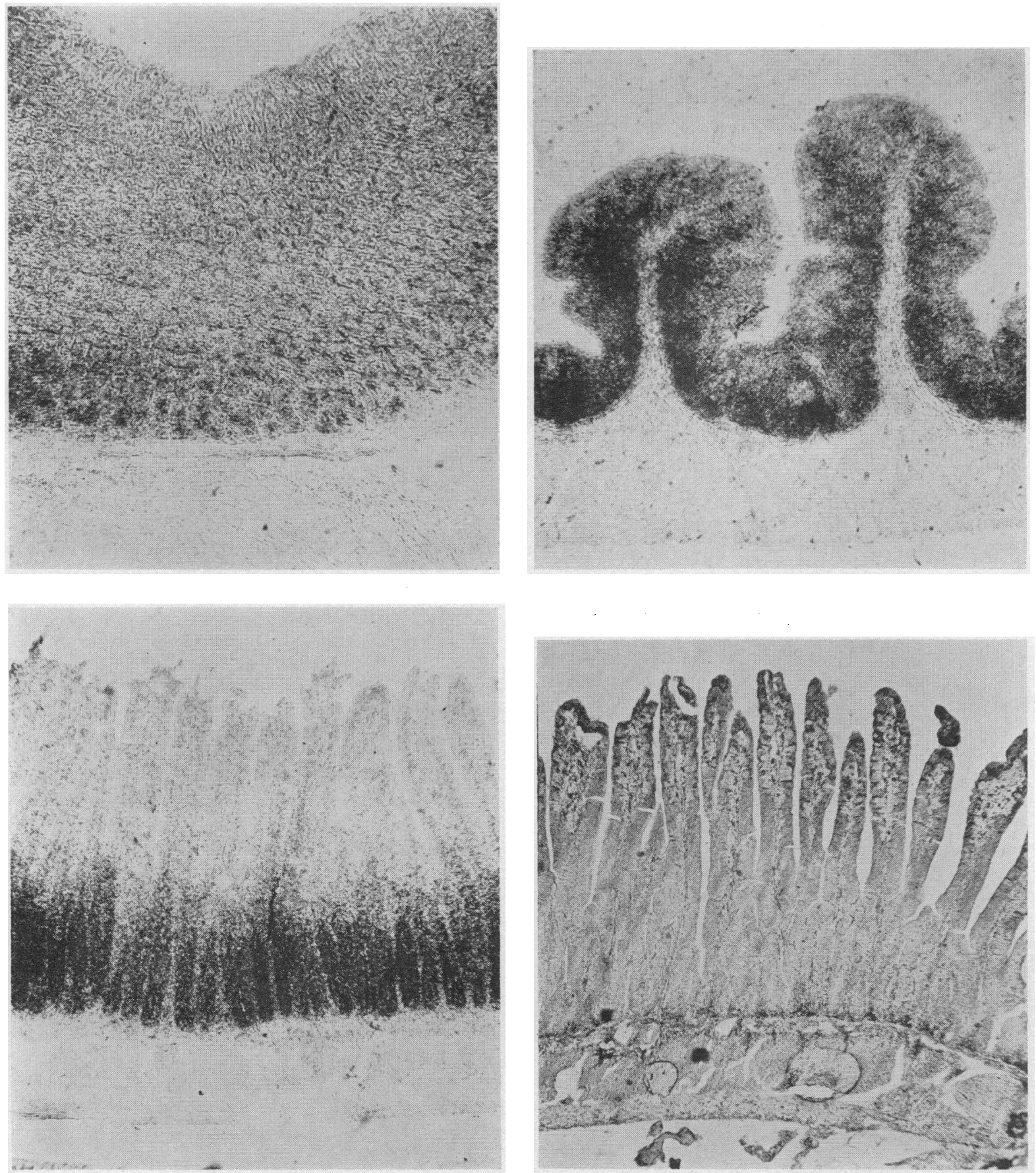

Fig. 1. Radioautographs After an iv doSe of iron ${ }^{59}$. Normal rat stomach (upper left), colon (upper right), and proximal small intestine (lower left) 16 hours afterward showed radioactivity in the villous epithelium. In contrast, there was little or no iron $^{50}$ in the submucosal or muscular layers. Radioautographs of duodenojejunal junction 16 hours after injection of iron $^{50}$ showed labeling of the mucosal cells in the proximal portion of the villus. This suggested that the radioiron was concentrated in newly formed cells in the crypts of the small intestine. Presumably cells nearer the villus tip had been formed before injection of the iron $^{50}$ and had been satiated with cold iron. Seventy-two hours after administration of the radioiron all the mucosal cells of the small intestinal villi were labeled (lower right). 
tillation detector (Packard auto gamma spectrometer model 410A). Specimens were acid digested and diluted to $2 \mathrm{ml}$ before counting. Radioactivity in the specimen was compared to that in a $2-\mathrm{ml}$ reference standard containing a known proportion of the test dose. The quantities of chromium ${ }^{51}$ and iron $^{50}$ in stool specimens were differentiated by use of the discriminator circuit in this device (8).

Blood loss in stool was measured after transfusion of $\mathrm{Cr}^{51}$-labeled red cells (9). Four $\mathrm{ml}$ of blood was autotransfused into the jugular vein after 30 minutes of incubation with $20 \mu \mathrm{c}$ of chromium $^{51}$. Specimens of stool were manually collected each day from the rats to avoid urinary contamination. The radioactivity in these samplings was considered representative of daily fecal loss. Rats were housed in metabolic cages to permit quantification of the total daily fecal vo'ume.

Iron balance studies were performed on rats housed in individual plastic metabolic cages. Dietary consumption of milk containing $0.37 \mu \mathrm{g}$ of iron per $\mathrm{ml}$ was measured daily. Seven-day stool collections were accumulated for determination of radioactivity and total iron content. Chemical analysis of iron content was performed by a modification of the method of Ramsay (10). Total body radioactivity of each animal was measured weekly in the small-animal scintillation detector by the method described above (7).

Doses of iron are expressed in milligrams of elemental iron.

\section{Results}

Experiment 1: Accumulation of parenteral iron in intestinal mucosa

A. Radioautographs show iron ${ }^{59}$ concentrated in epithelial cells (Figure 1). Radioautographs were prepared from tissues of 6 normal rats killed 4, 16, and 72 hours after an iv dose of iron ${ }^{59}$. Radioactivity was evident in the epithelium of the stomach, small intestine, and colon, but the submucosal and muscular layers of these organs contained little radioiron. In jejunum and duodenum 4 and 16 hours after dosing, the proximal portion of the villi as well as the crypts contained more radioactivity than the older cells near the villous tip. Small intestine of rats killed 72 hours after injection of the test dose showed radioiron in all villous and cryptic epithelial cells. Epithelium of the stomach and colon contained radioiron, but the serial changes in location of radioactivity seen in the small intestinal mucosa were not observed. Radioautographs of the intestinal tissue of iron-loaded rats showed similar findings. Radioactivity in the small intestinal epithelium of iron-depleted animals was only slightly

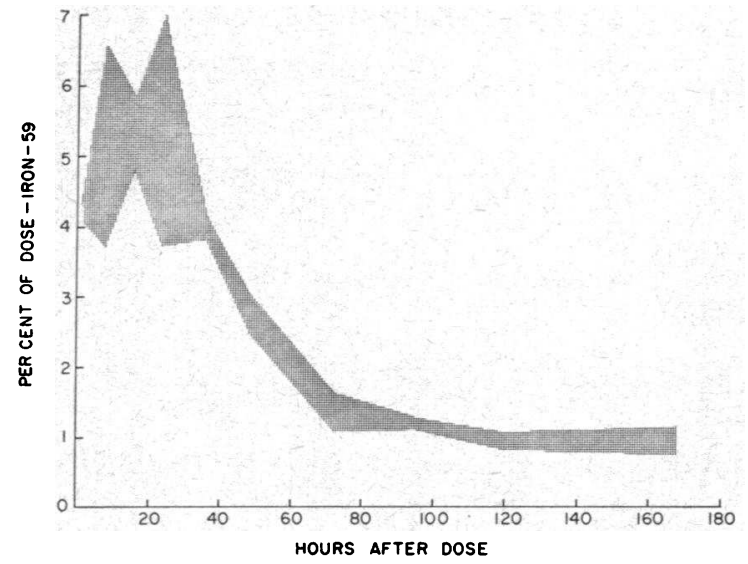

Fig. 2. IRON ${ }^{60}$ CONTENT OF SMALL INTESTINE AFTER AN IV DOSE. The quantity of iron $^{58}$ sequestered by the small intestine was measured at periodic interva!s after injection of an iv dose. The radioactivity in the excised small intestine increased for 24 hours after administration of the test dose. During the subsequent 48 hours there was a rapid decline in the quantity of iron ${ }^{50}$ detected in the intestinal segment. Since the rate of loss approximated the life-span of villous mucosal cells, we believed the iron ${ }^{50}$ was lost with a sloughed epithelium. The shaded area depicts the range of observed values converted to percentage of the test dose.

greater than background scatter. Radioautographs of various other organs showed iron ${ }^{59}$ concentrated in the bronchial epithelium, the acinar cells of the pancreas, the epithelium of the seminiferous tubules, renal tubular epithelium, and the glandular epithelium of the skin.

$B$. Changing concentrations of iron ${ }^{59}$ in intestine were observed at intervals after an iv dose (Figure 2). Thirty normal rats were given $5 \mu \mathrm{c}$ of radioiron intravenously and killed in groups of 3 at intervals after dosing. The entire small intestine was excised and assayed for iron $^{59}$ in a small animal scintillation detector. Two hours after dosing, $4.2 \%$ of the radioactivity was in the small intestine. The iron ${ }^{59}$ content gradually increased, reaching a maximal concentration of $5.8 \%$ at 24 hours. Thereafter, radioactivity decreased until at 72 hours only $1.3 \%$ of the test dose was present in the small intestine, and at 120 and 168 hours, $0.9 \%$. Sections of pectoral muscle were excised from these animals and assayed for radioactivity. A mass of muscle similar in weight to the gut segments would contain 0.5 to $0.6 \%$ of the test dose of iron $^{59}$ throughout the period of observation. 
TABLE I

Distribution of iron in the intestinal tract after an iv dose

\begin{tabular}{|c|c|c|c|c|c|c|c|c|c|c|}
\hline & & \multicolumn{9}{|c|}{ Iron $^{59}$} \\
\hline & & \multicolumn{3}{|c|}{ Small intestine } & \multicolumn{3}{|c|}{ Stomach } & \multicolumn{3}{|c|}{ Colon } \\
\hline & & $4 \mathrm{hrs}$ & $24 \mathrm{hrs}$ & $168 \mathrm{hrs}$ & $4 \mathrm{hrs}$ & $24 \mathrm{hrs}$ & $168 \mathrm{hrs}$ & $4 \mathrm{hrs}$ & $24 \mathrm{hrs}$ & $168 \mathrm{hrs}$ \\
\hline & & $\%$ & $\%$ & $\%$ & $\%$ & $\%$ & $\%$ & $\%$ & $\%$ & $\%$ \\
\hline Normal & $\mathrm{SE}$ & $\begin{array}{l}6.60 \\
0.44\end{array}$ & $\begin{array}{l}7.30 \\
0.67\end{array}$ & $\begin{array}{l}0.91 \\
0.02\end{array}$ & $\begin{array}{l}0.32 \\
0.03\end{array}$ & $\begin{array}{l}0.31 \\
0.03\end{array}$ & $\begin{array}{l}0.33 \\
0.02\end{array}$ & $\begin{array}{l}0.78 \\
0.10\end{array}$ & $\begin{array}{l}0.85 \\
0.08\end{array}$ & $\begin{array}{l}0.33 \\
0.04\end{array}$ \\
\hline Iron deficient & $\mathrm{SE}$ & $\begin{array}{l}3.63 \\
0.33\end{array}$ & $\begin{array}{l}2.91 \\
0.04\end{array}$ & $\begin{array}{l}0.76 \\
0.06\end{array}$ & $\begin{array}{l}0.22 \\
0.02\end{array}$ & $\begin{array}{l}0.24 \\
0.02\end{array}$ & $\begin{array}{l}0.28 \\
0.06\end{array}$ & $\begin{array}{l}0.38 \\
0.05\end{array}$ & $\begin{array}{l}0.43 \\
0.07\end{array}$ & $\begin{array}{l}0.28 \\
0.03\end{array}$ \\
\hline Iron loaded & $\mathrm{SE}$ & $\begin{array}{l}6.60 \\
0.60\end{array}$ & $\begin{array}{l}6.79 \\
0.50\end{array}$ & $\begin{array}{l}0.87 \\
0.08\end{array}$ & $\begin{array}{l}0.38 \\
0.11\end{array}$ & $\begin{array}{l}0.43 \\
0.11\end{array}$ & $\begin{array}{l}0.28 \\
0.07\end{array}$ & $\begin{array}{l}1.12 \\
0.13\end{array}$ & $\begin{array}{l}1.32 \\
0.16\end{array}$ & $\begin{array}{l}0.43 \\
0.07\end{array}$ \\
\hline
\end{tabular}

C. The state of iron repletion influenced the quantity of iron concentrated in the gut (Table I). The amount of iron sequestered by the small intestine after an iv dose of $5 \mu \mathrm{c}$ of radioactive iron ${ }^{59}$ was determined at intervals in 18 normal, 18 irondeficient, and 18 iron-loaded rats. The quantities of radioiron detected in the small intestine were similar in the normal and the iron-loaded rats. The small intestine of iron-deficient animals contained approximately half the quantity of injected iron $^{59}$ detected in normal rats; the radioactivity in these small intestinal segments did not increase

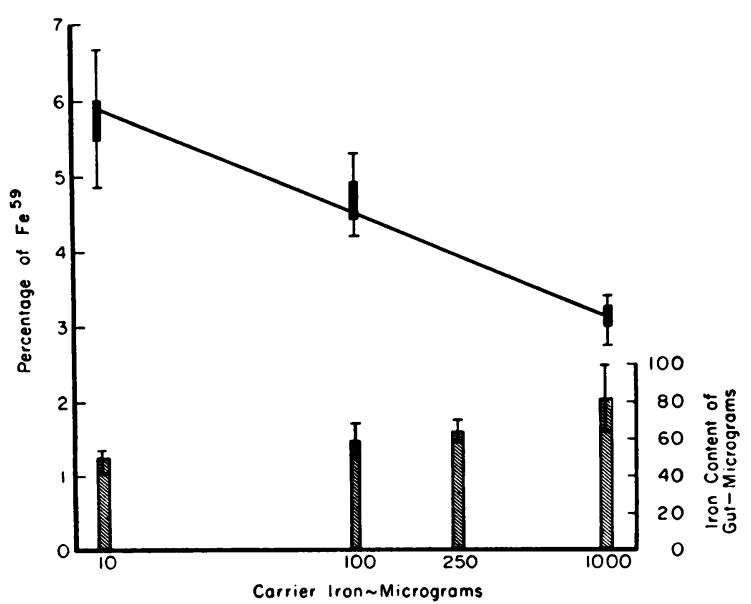

Fig. 3. Iron CONTENT OF SMALL INTESTINE AFTER VARIous PARENTERAL DOSES OF IRON. The amount of iron sequestered by the small intestine was measured 24 hours after injection of various doses of iron. Although the quantity of iron concentrated in gut segments increased with increasing doses of iron, the percentage of the iv dose sequestered by the small intestine decreased. Brackets indicate the range of observed values. Shaded areas within the brackets are the standard error of the mean. during the first day and was greater at 4 hours after the test dose than at 24 hours. The colon of normal rats contained $0.8 \%$ of the test dose of iron $^{59}$ both at 4 hours and at 24 hours after injection. The colon of iron-loaded rats contained more iron $^{59}(1.2 \%)$, and that of iron-deficient rats contained less $(0.4 \%)$ of the test dose than the colon of normal animals $(0.8 \%)$. Each group of rats had 0.2 to $0.4 \%$ of the iron ${ }^{59}$ in the colon 168 hours after injection of the test dose. Approximately $0.3 \%$ of the radioactive iron was detected in the stomach, and there was no significant change in the concentration of radioactive iron at intervals after dosing.

$D$. Larger parenteral doses of iron were concentrated less efficiently in the small intestine (Figure 3). The quantity of iron present in the entire small intestine of 18 normal rats was measured by chemical analysis 24 hours after iv administration of iron and found to be increased in proportion to the size of the injected dose. The mean iron content of the small intestine of 6 undosed rats was $41.6 \mu \mathrm{g}$; after $0.1 \mathrm{mg}$ it was 47.2 $\mu \mathrm{g}$, and after $1.0 \mathrm{mg}$ it was $67.2 \mu \mathrm{g}$. An additional 18 rats were divided into three equal groups and given intravenously $5 \mu \mathrm{c}$ of iron $^{59}$ with carrier doses of 0.01 to $1 \mathrm{mg}$ of iron. Thereafter, the mean concentration of iron ${ }^{59}$ in the small intestine was inversely proportional to the amount of cold iron injected, varying from 3.1 to $5.8 \%$ of the radioactive dose. A linear relationship existed between the percentage of iron $^{59}$ sequestered by the small intestine and the log of the dose of cold iron. 


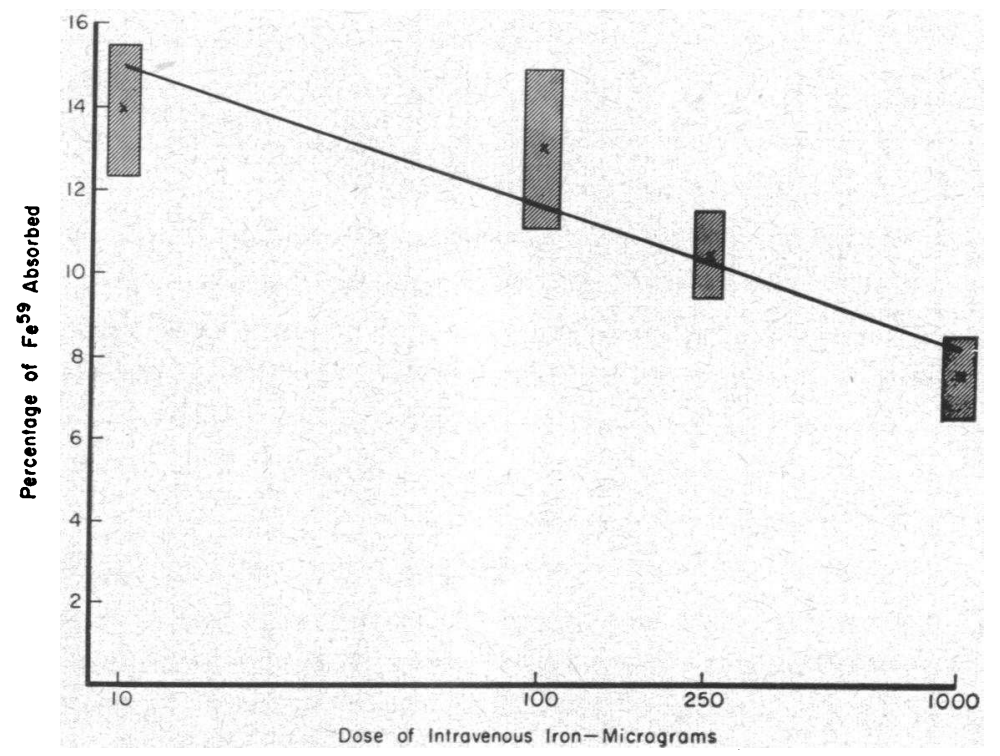

Fig. 4. Absorption of IRON 24 hours after AN IV DOSE OF IRON. Twenty-four hours after the iv injection of cold iron there was decreased absorption of an oral dose of iron ${ }^{50}$. The percentage of the radioiron absorbed was inversely proportional to the iv dose. Shaded area represents the standard error of the mean $(X)$.

Comment. The epithelial cells of many organs concentrate parenteral iron whether the dose is administered as a salt or bound to plasma protein $(6,11)$. In the case of many tissues this iron can be retrieved and reutilized by the body when the epithelial cell is destroyed at the end of its lifespan. In organs where epithelial cells are sloughed from a body surface, their content, including iron, is lost to the body. In a tissue such as the small intestine, where cell turnover occurs every 2 days (12), this could result in an appreciable loss of body iron. In addition, since absorption of iron must be controlled through the mucosal epithelium of the small intestine, we have proposed that variability of the iron content of these cells might be important in regulating the absorption of dietary iron. Our initial experiments were performed to study the way the small intestine utilizes body iron. In normal rats approximately $6 \%$ of an iv dose of radioiron (1.0 $\mu \mathrm{g})$ is concentrated in the small intestine during the 24 hours after injection. Then there is gradual disappearance of tracer iron from the small intestine within the turnover time of the intestinal cells (12). Seventy-two hours after the injection the concentration of radioiron in the small intes- tine is only slightly in excess of that detected in other body tissues. When a larger dose of iron is injected, the quantity sequestered by the small intestine increases but not in proportion to the dose. There is an inverse relationship between the quantity of iron administered and the percentage sequestered by the small intestine. This inverse exponential relationship resembles absorption studies where the percentage absorbed decreases although the total absorption increases $(7,13)$.

\section{Experiment 2: Effect of intestinal iron content upon absorption}

A. Injection of iron produced decreased absorption from the gut lumen (Figure 4). Absorption of an oral dose of radioiron was studied in 38 rats 24 hours after iv administration of cold iron. The animals were divided into four groups and given iv doses of ferrous sulfate varying from 0.01 $\mathrm{mg}$ to $1 \mathrm{mg}$. Iron absorption studies were initiated the following day. Mean absorption of the test dose was inversely proportional to the quantity of iron administered intravenously, varying from 7.6 to $13.9 \%$. A linear relationship was 
TABLE II

Iron absorption at intervals after iv administration of ferrous sulfate $(0.25 \mathrm{mg})$

\begin{tabular}{|c|c|c|c|c|}
\hline \multicolumn{5}{|c|}{ Oral dose of iron ${ }^{59}$ absorbed } \\
\hline \multicolumn{2}{|c|}{ No iv iron } & $\begin{array}{l}\text { Concurrent } \\
\text { iv and } \\
\text { oral dose }\end{array}$ & $\begin{array}{l}\text { iv iron } \\
24 \text { hours } \\
\text { before } \\
\text { oral dose }\end{array}$ & $\begin{array}{l}\text { iv iron } \\
168 \text { hours } \\
\text { before } \\
\text { oral dose }\end{array}$ \\
\hline & $\%$ & $\%$ & $\%$ & $\%$ \\
\hline & 8.49 & 6.34 & 3.19 & 7.41 \\
\hline & 9.66 & 7.06 & 4.00 & 10.02 \\
\hline & 10.89 & 7.61 & 4.25 & 10.98 \\
\hline & 11.18 & 7.79 & 4.36 & 12.34 \\
\hline & 11.40 & 8.73 & 4.92 & 12.34 \\
\hline & 13.47 & 8.75 & 5.42 & 12.72 \\
\hline & 13.77 & 11.05 & 5.61 & 13.51 \\
\hline & 19.63 & 11.16 & 5.70 & 16.66 \\
\hline & 20.63 & 12.70 & 6.29 & 17.31 \\
\hline & 21.59 & 13.44 & 7.26 & 22.02 \\
\hline Mean & 14.07 & 9.46 & 5.10 & 13.53 \\
\hline SE & 1.52 & 0.78 & 0.37 & 1.27 \\
\hline
\end{tabular}

found between the percentage of iron ${ }^{59}$ absorbed and the log of the iv dose.

B. Absorption of iron was decreased at the time parenteral iron was concentrated in intestinal epithelium (Table II). Absorption of an oral dose of iron $^{59}$ was studied at intervals after iv administration of $0.25 \mathrm{mg}$ ferrous sulfate. Untreated, normal rats absorbed $14 \%$ of the oral test dose of radioiron. Twenty-four hours after the injection of ferrous sulfate only $5 \%$ of the oral dose was absorbed. Greater absorption of the oral dose of iron $^{59}$ was observed when it was administered immediately after the parenteral injection $(9.5 \%)$ or long after it ( 7 days, $13.5 \%)$. Thus iron absorption was maximally depressed when body iron was concentrated in intestinal epithelium but not when it was circulating in the plasma or fixed in body stores.

C. Normal absorption of iron may be observed in iron-loaded animals (Table III). That the total body store of iron was not in constant equilibrium with iron in intestinal mucosa was determined in iron-loaded rats subjected to bloodletting. Dextran iron $(12.5 \mathrm{mg})$ was administered by im injection to 28 rats. Two weeks later half the treated group was bled $5 \mathrm{ml}$, leaving each phlebotomized animal with $10 \mathrm{mg}$ of excess iron. Five days after phlebotomy the proximal quarter of the small intestine was excised from 7 normal, 7 iron-loaded, and 7 iron-loaded bled rats and assayed for nonheme iron content. An iron absorption study was initiated in similar groups of rats. Normal animals absorbed $10.5 \%$ of an oral dose of iron and had $12.5 \mu \mathrm{g}$ of iron per $\mathrm{g}$ of excised intestine. Unbled iron-loaded animals absorbed only half this quantity of iron but had twice the concentration of iron in their intestinal segments. There was no marked difference between the values observed in the iron-loaded bled animals and normal rats. ${ }^{1}$

Comment. In the previous experiment we showed that a parenteral dose of iron was concentrated in intestinal mucosal cells (experiment

\footnotetext{
1 Chemical analysis of bled iron-loaded rats was the same as normal animals, but in the bled iron-loaded animals hemosiderin was demonstrated in the submucosa by the Prussian blue reaction. Iron was concentrated in a location and form different from that present in normal animals.
}

TABLE III

Effect of phlebotomy in the iron-loaded rat: $F e^{59}$ asborbed versus iron content of intestinal segment

\begin{tabular}{|c|c|c|c|c|c|c|}
\hline & \multicolumn{2}{|c|}{ Normal } & \multicolumn{2}{|c|}{ Iron-loaded } & \multicolumn{2}{|c|}{ Iron-loaded, bled $5 \mathrm{ml}$} \\
\hline & Absorption & Iron content & Absorption & Iron content & Absorption & Iron content \\
\hline & $\begin{array}{c}\% \\
5.17 \\
6.61 \\
8.68 \\
11.68 \\
11.70 \\
14.54 \\
14.93\end{array}$ & $\begin{array}{c}\mu g / g \\
9.40 \\
11.60 \\
11.66 \\
11.85 \\
12.01 \\
12.43 \\
18.26\end{array}$ & $\begin{array}{c}\% \\
2.61 \\
3.35 \\
3.57 \\
4.99 \\
5.21 \\
6.87 \\
7.49\end{array}$ & $\begin{array}{c}\mu g / g \\
17.42 \\
24.84 \\
27.24 \\
28.42 \\
30.15 \\
31.11 \\
31.36\end{array}$ & $\begin{array}{c}\% \\
7.09 \\
8.49 \\
10.29 \\
12.65 \\
13.17 \\
14.40 \\
16.40\end{array}$ & $\begin{array}{c}\mu g / g \\
11.00 \\
11.85 \\
12.68 \\
16.61 \\
18.39 \\
20.69 \\
23.31\end{array}$ \\
\hline Mean & 10.47 & 12.45 & 4.87 & 27.22 & 11.78 & 16.36 \\
\hline SD & 3.77 & 2.73 & 1.83 & 4.89 & 3.52 & 4.72 \\
\hline $\mathrm{SE}$ & 1.42 & 1.03 & 0.70 & 1.84 & 1.33 & 1.78 \\
\hline
\end{tabular}


1A) and that maximal concentration was achieved 16 to 24 hours after the iv injection (experiment $1 \mathrm{~B})$. In the present experiment we demonstrated decreased absorption of iron during the same period that the parenteral dose was concentrated in the intestinal epithelium (experiment 2B). Further, we showed decreases in absorption after graduated increases in the parenteral dose of iron (experiment 2A). Small quantities of iron were used for injection to prevent significant dilution of the oral test dose within the gut lumen. Our parenteral dose was sufficiently small that it did not measurably alter absorption once it was fixed in the body stores (experiment. 2B). The relationship between the intestinal iron content and

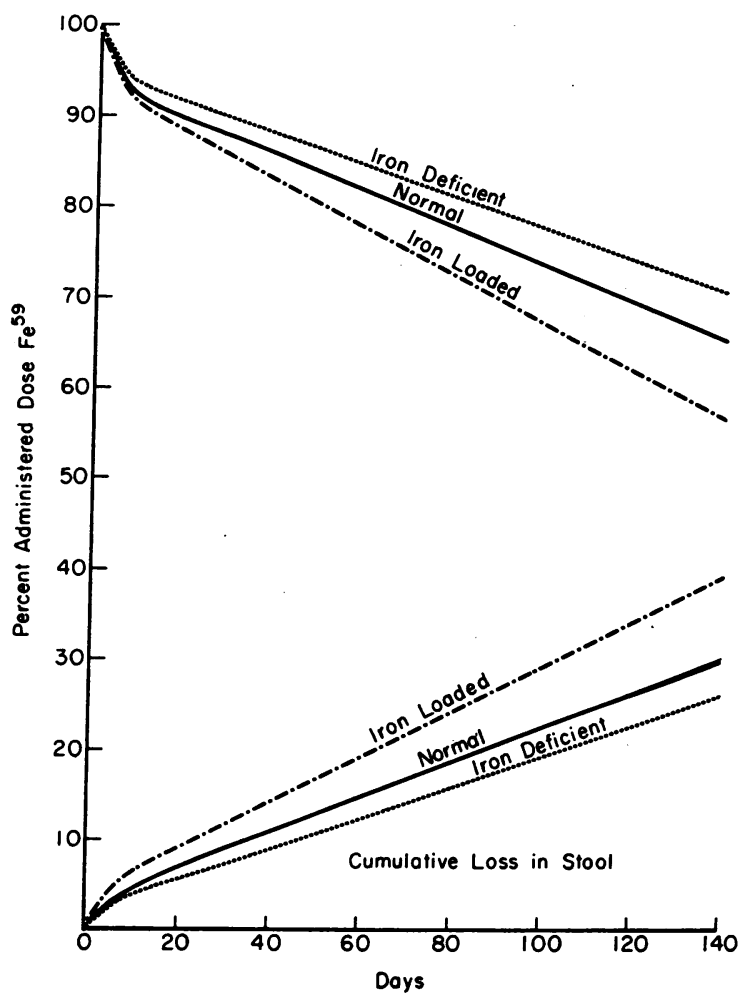

Fig. 5. Retention of PARENTERAL dOSE OF IRON ${ }^{50}$ IN RATS. Body retention of a parenteral dose of iron was measured weekly in groups of 4 normal, 4 irondepleted, and 4 iron-loaded rats with a small animal liquid scintillation detector. There was corresponding decrease in body retention and recovery of the test dose in accumulating fecal collections. Loss of iron ${ }^{50}$ seemed to be selective and depend upon the state of iron repletion of the test animal. The observations were significantly different as determined by the $95 \%$ confidence limits of the regression coefficients (15).

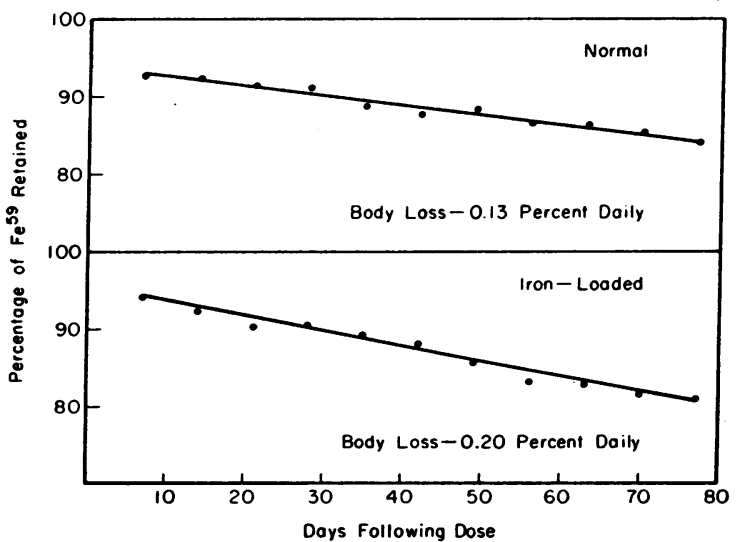

Fig. 6. Whole body Retention of PaRenteral Dose OF IRON $^{\text {65. }}$. Mean retention of a parenteral dose of iron $^{50}$ was measured weekly in groups of 6 rats with a small animal liquid scintillation detector. Normal rats consuming an iron-deficient milk diet lost an average of $0.13 \%$ of the test dose daily. Iron-loaded rats had a daily loss of $0.20 \%$ of the iv iron ${ }^{50}$. There was a significant difference in the regression coefficients as determined by the $t$ test $(\mathrm{p}>.05)(15)$.

the quantity of iron absorbed led us to believe that the iron content of intestinal epithelium acts to regulate absorption $(3,14)$. Previous investigators have doubted this hypothesis because increased absorption has been shown in certain conditions with increased iron stores (4). This paradox may be explained by our demonstration (experiment $2 \mathrm{C}$ ) that the body stores are not in constant equilibrium with the iron content of intestinal mucosal cells.

\section{Experiment 3: Loss of parenteral iron from the intestine}

A. Loss of iron from the body was selective, depending upon the state of iron repletion (Figure 5 ). Retention in the body of a parenteral dose of radioiron ${ }^{59}$ was measured twice weekly in 4 normal, 4 iron-depleted, and 4 iron-loaded rats with a small-animal liquid scintillation detector. Cumulative stool collections from each group were assayed weekly for radioiron. Each rat lost 4 to $9 \%$ of the test dose of iron ${ }^{59}$ during the week after injection. Then there was a slower linear loss of radioactivity in the stool. Five months after administration of the iron ${ }^{59}$, normal rats retained 60 to $70 \%$ of the test dose. At that time there was a continuing daily loss in the 
TABLE IV

Iron balance: mean daily loss of iron

\begin{tabular}{|c|c|c|c|c|c|}
\hline & \multirow{2}{*}{\multicolumn{2}{|c|}{$\begin{array}{c}\text { Intake } \\
\text { Diet }\end{array}$}} & \multirow{3}{*}{$\frac{\text { Output }}{\substack{\text { Fecal } \\
\text { Iron }}}$} & \multirow{3}{*}{$\begin{array}{l}\begin{array}{l}\text { Net } \\
\text { loss }\end{array} \\
\text { Iron }\end{array}$} & \multirow{3}{*}{$\begin{array}{c}\text { Stool } \\
\text { recovery } \\
\text { of iv } \\
\text { dose of } \\
\text { iron } \\
59\end{array}$} \\
\hline & & & & & \\
\hline & Milk & Iron & & & \\
\hline Normal & $\begin{array}{c}m l \\
84.7\end{array}$ & $\begin{array}{c}\mu g \\
31.3\end{array}$ & $\begin{array}{c}\mu g \\
42.9\end{array}$ & $\begin{array}{c}\mu g \\
11.6\end{array}$ & $\begin{array}{c}\% \\
0.14\end{array}$ \\
\hline Iron loaded & 85.4 & 31.6 & 81.0 & 49.4 & 0.22 \\
\hline
\end{tabular}

stool of $0.2 \%$ of the radioactive iron. Iron-depleted rats lost less and iron-loaded rats more of the test dose than normally iron-replete animals.

$B$. Comparative losses of body iron in various states of iron repletion were underestimated by radioisotopic studies (Figure 6, Table IV). To compare actual loss of body iron and loss of a tracer dose of iron $^{59}, 6$ normal and 6 iron-loaded rats were injected with iron $^{59}$ and housed in plastic metabolic cages. Accumulating fecal collections were assayed for radioactivity and total iron content. On an unrestricted milk diet each animal consumed an average of $85 \mathrm{ml}$ daily, amounting to $31.5 \mu \mathrm{g}$ of iron. Cumulative stool collections from normal rats showed a mean daily loss of $42.9 \mu \mathrm{g}$ of iron and $0.14 \%$ of the radioactive
TABLE $\mathrm{V}$

Loss of $C r^{51}-$ labeled erythrocytes aud $F e^{59}$ in stool

\begin{tabular}{llr}
\hline & $\mathrm{Cr}^{51}$ & $\mathrm{Fe}^{59}$ \\
\hline & \multicolumn{2}{c}{$\mathrm{mm}^{3}$ blood $/$ day } \\
Normal & $24 \pm 1.6^{*}$ & $27 \pm 1.2$ \\
Iron deficient & $23 \pm 1.4$ & $22 \pm 1.1$ \\
Iron loaded & $24 \pm 1.2$ & $35 \pm 1.7$ \\
\hline
\end{tabular}

* Variation is expressed as standard error of the mean of 40 daily determinations.

dose. Iron-loaded animals had an average daily fecal loss of $81 \mu \mathrm{g}$ of iron and $0.22 \%$ of the iron ${ }^{59}$. Weekly assay of total body radioactivity in these rats showed comparable rates of loss of iron $^{59}$. Chemical measurements of net daily fecal loss of body iron from iron-loaded animals $(41 \mu \mathrm{g})$ and normal rats on an iron-deficient diet $(11 \mu \mathrm{g})$ showed greater differences between groups than was observed by radioisotopic methods $(0.22 \%$ versus $0.14 \%$ ). This difference was caused by the variation in size of the iron pool with which the test dose of iron ${ }^{59}$ mixed after injection.

C. All rats lost similar quantities of hemoglobin iron, but fecal losses of nonheme iron varied with the state of iron repletion (Figure 7, Table $V$ ). Fecal loss of blood and iron ${ }^{59}$ was measured in 2

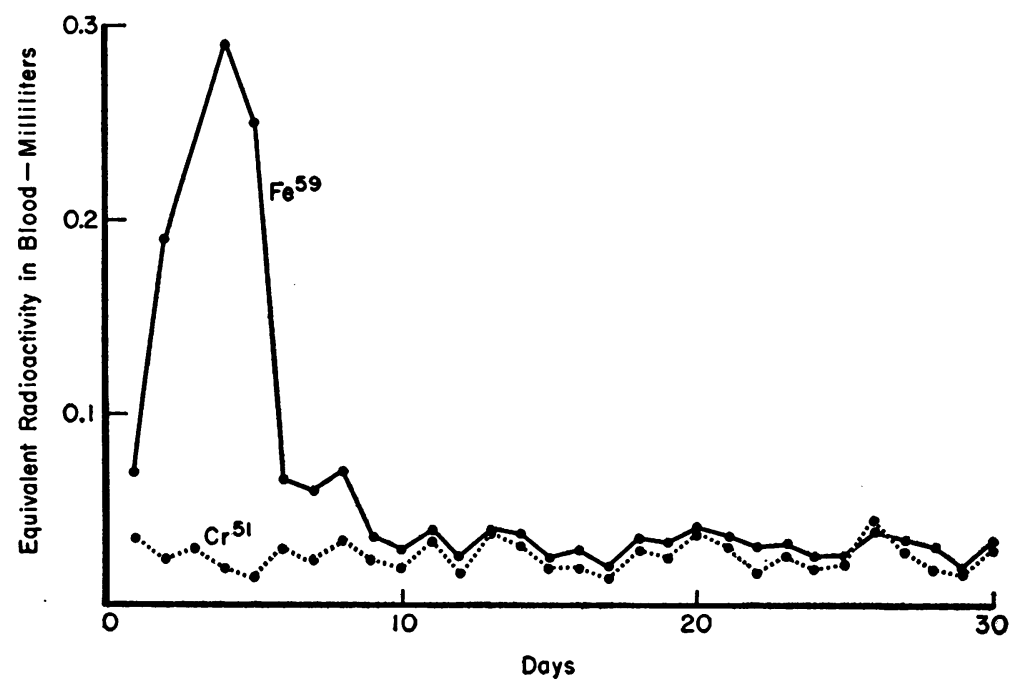

Fig. 7. LosS OF CHROMIUM ${ }^{51}$-LABELED ERYTHROCYTES AND IRON ${ }^{50}$ IN STOOL oF NORMAL RAT. Gastrointestinal blood loss was quantified by measurement of chromium ${ }^{59}$ in daily fecal collections. Loss of an iv dose of iron $^{58}$ was measured in fecal collections and compared to the quantity of this radionuclide in $1 \mathrm{ml}$ of blood. Initially iron was lost in significantly greater quantities than anticipated from blood loss. Later losses of iron were only slightly in excess of that expected from bleeding. 
normal, 2 iron-depleted, and 2 iron-loaded rats. After autotransfusion of $4 \mathrm{ml}$ of $\mathrm{Cr}^{51}$-labeled red cells and an iv injection of $5 \mu \mathrm{c}$ of radioiron ${ }^{59}$, urine-free stools were collected daily from these animals. All rats lost an average of $24 \mathrm{~mm}^{3}$ of blood daily measured by the $\mathrm{Cr}^{51}$ method. During the week after the injection, the fecal iron ${ }^{59}$ greatly exceeded the radioactivity expected from blood loss. During the period 10 to 30 days after injection, the daily losses of radioactive iron from normal rats equaled the amount of iron ${ }^{59}$ detected in $27 \mathrm{~mm}^{3}$ of blood. The fecal iron loss in the iron-loaded rats corresponded to $35 \mathrm{~mm}^{3}$ of blood per day, appreciably more than they appeared to lose by the $\mathrm{Cr}^{51}$ method and correspondingly more than the normal animals lost. The daily fecal decrement of iron in the iron-deficient rats approximated that expected from blood loss (23 $\mathrm{mm}^{3}$ ) measured by $\mathrm{Cr}^{51}$ recovery.

D. Excess iron was more efficiently lost from the body when injected in small increments rather than as a single dose (Table VI). To ascertain if the rate of administration altered the intestinal loss of a dose of iron, 8 rats were injected intraperitoneally with $0.5 \mu \mathrm{c}$ of iron $^{59}$ in $1.0 \mathrm{mg}$ of ferrous sulfate. Iron was administered to half the group as a single injection and to the remaining 4 in twenty equal daily doses. Animals receiving single doses of iron lost approximately $10 \%$ of the radioactivity within 30 days after injection. Rats receiving the same total dose in small increments lost twice the quantity of iron ${ }^{59}$ in the same interval. Fecal loss of radioiron was similar in both groups during the second month of observation. If we assume that excess iron may be shed with exfoliating epithelium, and since it was shed more efficiently when administered in daily increments rather than as a single dose, the epithelial cells must receive a larger percentage of a small dose.

Comment. The capability of the intestine to rid the body of excess iron appears to be limited but selective (experiment 3A) (16). Since the quantity of injected iron entering intestinal cells varies with the size of the test dose (experiment 1D) and the state of body repletion (experiment $1 \mathrm{C}$ ), so the amount lost into the feces is influenced by these variables. Thus there is greater loss of excess iron when it is injected in small
TABLE VI

Retention of iron ${ }^{59}$ after single and multiple parenteral doses

\begin{tabular}{|c|c|c|c|c|}
\hline \multirow[b]{3}{*}{ No. } & \multicolumn{4}{|c|}{ Iron 59 retained } \\
\hline & \multicolumn{2}{|c|}{ Single dose } & \multicolumn{2}{|c|}{20 daily doses } \\
\hline & 30 days & 60 days & 30 days & 60 days \\
\hline & $\%$ & $\%$ & $\%$ & $\%$ \\
\hline $\begin{array}{l}1 \\
2 \\
3 \\
4\end{array}$ & $\begin{array}{l}90.8 \\
95.4 \\
84.0 \\
93.0\end{array}$ & $\begin{array}{l}84.6 \\
87.5 \\
80.1 \\
86.3\end{array}$ & $\begin{array}{l}81.5 \\
80.7 \\
81.8 \\
80.2\end{array}$ & $\begin{array}{l}75.7 \\
73.2 \\
74.7 \\
76.0\end{array}$ \\
\hline Mean & 90.8 & 84.6 & 81.0 & 74.9 \\
\hline SE & 2.5 & 1.7 & 0.4 & 0.6 \\
\hline
\end{tabular}

increments rather than as a single dose (experiment $3 \mathrm{D})$. Also there is greater loss of iron in fecal collections from iron-loaded rats than from normal or iron-deficient animals (experiment 3A). In our experiments iron-deficient rats lost only an amount of iron corresponding to the hemoglobin in stool (experiment 3C). Chemical analysis showed that iron-loaded rats lost four times more iron than normal animals on an irondeficient diet (experiment 3B). Thus the body iron content is apparently regulated by selective loss as well as controlled absorption.

\section{Discussion}

We have demonstrated by radioautography that oral and parenterally administered iron is incorporated into the epithelial cells of the small intestine of normal rats. Iron administered by mouth accumulated in the absorptive epithelial cells covering the intestinal villi; in normal animals some of this iron remained until the cells were finally desquamated (6). Intravenous iron was incorporated into the intestinal epithelial cells of the small intestine of normal and iron-loaded rats at the time the cells were formed in the crypts of Lieberkühn. There was no such concentration of parenteral iron in iron-deficient animals. On the basis of these results, we proposed a hypothesis to explain the intestinal control of iron absorption : depending upon information concerning the body's requirement for iron, more or less of what may be called "messenger iron" is incorporated into newly forming absorptive epithelial cells of the small intestine. A large dose of messenger iron reflects an iron-loaded state; 
such epithelial cells are able to reject almost all of the available dietary iron. In iron deficiency the cells are formed with little or no messenger iron, and through such cells there is relatively free passage of dietary iron into the body. Intermediary states are represented by various amounts of messenger iron according to the requirements of the body.

The radioautographs indicated the presence of parenteral iron incorporated into newly formed intestinal cells (6). The present studies have provided quantitative data concerning the behavior of intestinal iron; these data seem to support the proposed hypothesis.

Significant quantities of the iv test dose of iron ${ }^{59}$ were detected in gut segments during the life-span of the small intestinal epithelium (experiment 1B above) (12). This preferential accumulation of iron in intestine (experiment 1A) during a brief period of time permitted study of the effect upon iron absorption of small parenteral doses of iron in relation to their concentration in intestinal epithelium.

Serial decreases in absorption of an oral dose of iron occurred when they were preceded by iv injection of increasing amounts of iron (experiment 2A). A similar inverse exponential relationship was observed between the percentage of an iv dose of radioiron sequestered by the gut and the size of an accompanying carrier dose (experiment 1D). This suggested a correlation between the concentration of iron in intestinal mucosal cells and the amount of iron accepted from the gut lumen. If the correlation exists, the gradients we observed might explain why as the size of an oral dose increases, the total amount of iron absorbed also increases although the percentage retained becomes less $(7,13)$.

To test further the hypothesis that the mucosal content of iron influences the quantity absorbed, absorption of oral iron ${ }^{59}$ was measured at various intervals after iv injection of cold iron (experiment 2B). Absorption was least at the time the parenteral dose was maximally concentrated within the intestinal epithelium. Injected iron exerted less effect upon absorption during the period it was circulating in the plasma or fixed in body stores. This confirms previous observations that iron absorption is not controlled directly by either the plasma iron concentration or the size of the body store $(17,18)$.

The paradox of normal or increased intestinal absorption of iron by iron-loaded animals with accelerated erythropoiesis was studied in bled, iron-loaded rats (experiment 2C) (18). Although the total body store of iron remained excessive, there was relative depletion of iron from intestinal segments. We believed that preferential utilization of iron by the bone marrow reduces sequestration of iron by the gut and that this produces increased absorption of iron, probably continuing until sufficient iron is mobilized from fixed stores to establish a new state of iron equilibrium.

To explain our observations, we postulated that the columnar epithelial cells of the small intestine act as individual units to regulate iron equilibrium. The iron content of these cells is regulated by body requirements and seems to be controlled through the plasma iron turnover (19). Body iron not in demand elsewhere is available to enter the intestinal cell during its formation in the crypts and remains within the cell as it migrates towards the villous tip (experiment 1A). The amount of this messenger iron varies according to the body's requirement at the time the cell is formed, and subsequently it determines the amount of dietary iron the cell can accept while serving as an absorptive unit. As cells move along the villus, they accept a portion of the iron present in the gut lumen, the quantity being limited by their own intrinsic iron content (experiments $2 \mathrm{~A}$ and $\mathrm{B}$ ). Needed iron is received from the intestinal cell by the body. That which is not needed remains within the cell to be lost when the mucosal cell is desquamated at the end of its lifespan.

To exemplify this concept whereby the small intestine controls absorption of iron, we considered three states of iron equilibrium: normal, iron excess, and iron deficiency. We have postulated that in iron excess the intestinal mucosal cells are laden with body iron. This restricts the entry of dietary iron into the cell and thus into the body. The small quantity of dietary iron absorbed by iron-loaded animals is less than the amount lost by desquamation of iron-laden intestinal cells. In time, this negative iron balance 
would reduce the body store to normal levels (4, 20). In normal animals the cells are partially saturated with intrinsic iron, depending upon the state of body repletion. This allows a limited but significant quantity of dietary iron to enter the cell. Needed iron is absorbed from these mucosal cells, and the remainder is lost with sloughed epithelium. We predicated that in iron deficiency the cells contain little iron, which permits relatively uninhibited entry of dietary iron into the body. Since little iron is incorporated into these cells during their formation and most dietary iron entering these cells passes into the body, only the smallest amounts of iron-the cell's physiologically active iron-would be lost when the mucosal cells are sloughed from the villus at the end of their life-span.

The normal state of iron repletion and the two extremes-iron depletion and iron loading-are representative examples. Between them is probably a complete spectrum of graduated states that provoke graduated responses by the intestine. In any individual the state of iron repletion varies from time to time, depending upon the loss of hemoglobin or other iron and upon the amount of iron absorbed after each meal. In response to this variation the absorptive intestinal epithelial cells would, according to the proffered hypothesis, possess more or less capability to accept available iron from the diet. At any moment the epithelial pavement of the iron-absorptive portion of the gut would be a mosaic of cells of various capabilities, but their over-all capability would be an accurate reflection of the recent condition or events in the body's iron metabolism. Thereby the iron balance is maintained with elegant precision.

\section{Summary}

1. The iron content of the intestinal epithelium plays an important role in regulating the iron equilibrium of the body.

2. Iron from body pools can be concentrated in the small intestinal mucosa, where it may act to regulate the entry of dietary iron into the cell.

3. Needed iron can be transferred from intestinal cells into the body. Unneeded iron can be lost into the lumen of the gut when the mucosal cells are sloughed from the villus.
4. Iron is lost from the body in sloughed epithelium in a selective manner so that needed iron is conserved and excess eliminated.

\section{References}

1. Widdowson, E. M., R. A. McCance, and C. M. Spray. Chemical composition of the human body. Clin. Sci. 1951, 10, 113.

2. McCance, R. A., and E. M. Widdowson. The absorption and excretion of iron following oral and intravenous administration. J. Physiol. 1938, 94, 148.

3. Hahn, P. F., W. F. Bale, J. F. Ross, W. M. Ba!four, and G. H. Whipple. Radioactive iron absorption by the gastro-intestinal tract. Influence of anemia, anoxia and antecedent feeding. Distribution in growing dogs. J. exp. Med. 1943, 78, 169.

4. Moore, C. V. Iron Metabolism and Nutrition. The Harvey Lectures. New York, Academic Press, 1961, series 55 , p. 67.

5. Brückmann, G., and S. G. Zondek. An improved method for the determination of non-hemin iron. J. biol. Chem. 1940, 135, 23.

6. Conrad, M. E., Jr., and W. H. Crosby. Intestinal mucosal mechanisms controlling iron absorption. Blood 1963, 22, 406.

7. Forrester, R. H., M. E. Conrad, Jr., and W. H. Crosby. Measurement of total body iron ${ }^{50}$ in animals using whole-body liquid scintillation detectors. Proc. Soc. exp. Biol. (N. Y.) 1962, 111, 115.

8. Francis, J. E., P. R. Bell, and C. C. Harris. Medical scintillation spectrometry. Nucleonics 1955, 13, 82.

9. Bannerman, R. M. Measurement of gastrointestinal bleeding using radioactive chromium. Brit. med. J. 1957, 2, 1032.

10. Ramsay, W. N. M. The determination of iron in blood, plasma or serum. Clin. chim. Acta 1957, 2, 214.

11. Finch, C. A., M. Hegsted, T. D. Kinney, E. D. Thomas, C. E. Rath, D. Haskins, S. Finch, and R. G. Fluharty. Iron metabolism. The pathophysiology of iron storage. Blood 1950, 5, 983.

12. Hughes, W. L., V. P. Bond, G. Brecher, E. P. Cronkite, R. B. Painter, H. Quastler, and F. G. Sherman. Cellular proiiferation in the mouse as revealed by autoradiography with tritiated thymidine. Proc. nat. Acad. Sci. (Wash.) 1958, 44, 476.

13. Bothwell, T. H., G. Pirzio-Biroli, and C. A. Finch. Iron absorption I. Factors influencing absorption. J. Lab. clin. Med. 1958, 51, 24. 
14. Granick, S. Ferritin IX. Increase of the protein apoferritin in the gastrointestinal mucosa as a direct response to iron feeding. The function of ferritin in the regulation of iron absorption. J. biol. Chem. 1946, 164, 737.

15. Snedecor, G. W. Statistical Methods. Ames, Iowa, Iowa State College Press, 1956, p. 394.

16. Chappelle, E., B. W. Gabrio, A. R. Stevens, Jr., and C. A. Finch. Regulation of body iron content through excretion in the mouse. Amer. J. Physiol. $1955,182,390$.
17. Conrad, M. E., and W. H. Crosby. The natural history of iron deficiency induced by phlebotomy. Blood 1962, 20, 173.

18. Weintraub, L. R., M. E. Conrad, and W. H. Crosby. The role of hepatic iron stores in the control of iron absorption. J. clin. Invest. 1964, 43, 40.

19. Weintraub, L. R., M. E. Conrad, and W. H. Crosby. The significance of iron turnover in the control of iron absorption. Blood. In press.

20. Crosby, W. H., M. E. Conrad, Jr., and M. S. Wheby. The rate of iron accumulation in iron storage disease. Blood 1963, 22, 429. 